Anil Gudi · Al Samarrai

\title{
A 9-year experience of laparoscopic hysterectomy in a UK district general hospital
}

Received: 21 February 2005 / Accepted: 23 June 2005/ Published online: 26 August 2005

(C) Springer-Verlag Berlin / Heidelberg 2005

\begin{abstract}
Hysterectomy is the commonest major gynaecological operation. Laparoscopic hysterectomy now offers a means of converting an otherwise abdominal approach into a vaginal procedure. A UK district general hospital has evaluated its experience in laparoscopic hysterectomy over 9 years, starting at a point when abdominal hysterectomy was a norm in the UK. Three hundred and sixty-three women underwent laparoscopic hysterectomy from January 1993 to January 2002. Operating time averaged at $86.4 \mathrm{~min}$ while the hospital stay was 2.7 days. For 2 years ENDO GIA was used. Two hundred and ninety-seven cases of laparoscopic hysterectomy were performed where the cardinal and uterosacral ligaments were transected. Bowel complications were $0.55 \%$, ureteric complications were $0.55 \%$ while bladder complications were $0.826 \%$ and one patient died. The overall complication rate (minor and major) was $8.5 \%$. These rates are comparable with other studies of abdominal and laparoscopic hysterectomies. The uptake of laparoscopic hysterectomies continues to be low in the United Kingdom. To offer the benefits of laparoscopic hysterectomy it is important to dramatically increase the uptake of the minimal access route by aiming to change practice and training for this procedure.
\end{abstract}

Keywords Laparoscopic hysterectomy - Laparoscopic assisted vaginal hysterectomy · Ureteric injury in laparoscopic hysterectomy $\cdot$ Complication of hysterectomy

A. Gudi $(\bowtie)$

Department of Obstetrics and Gynaecology, Homerton University Hospital,

London, E9 6SR, UK

E-mail: gudiaa@aol.com

Fax: + 44-20-85107787

A. Samarrai

Department of Obstetrics and Gynaecology,

The Princess Alexandra Hospital NHS trust, Harlow,

Essex, CM20 1QX, UK

\section{Introduction}

Hysterectomy is the commonest major gynaecological operation, and a vast majority of procedures are performed for benign conditions. Approximately 72,821 hysterectomies were performed for benign disease in 1 year in the UK [1], and it is estimated that $16-20 \%$ of UK women will undergo hysterectomy by the age of 55 years $[2,3]$. Vaginal hysterectomy as compared with abdominal hysterectomy has been shown to offer a decreased risk of complications, shorter hospital stay, and more rapid recovery and return to normal activity [4]. There are contraindications to vaginal surgery, such as previous pelvic surgery, endometriosis, large uterus, suspected adnexal pathology and limited uterine motility. With the means of advances in laparoscopic surgical techniques and instrumentation, a combined approach is now possible. Laparoscopic-assisted vaginal hysterectomy [5] and the advent of total laparoscopic hysterectomy now offer a means of converting an otherwise abdominal approach to a vaginal procedure, theoretically maintaining the advantages of the vaginal approach. Many reports now favour operative laparoscopy over laparotomy for ectopic pregnancies, treatment of moderate and severe endometriosis, adnexectomy and ovarian cysts [6]. Proponents of laparoscopic methods cite shorter hospital stay and faster return to normal pre-operative life.

The purpose of this retrospective study is to evaluate and describe our experience of laparoscopic hysterectomy in a district general hospital and compare the differences in techniques (laparoscopic total and assisted vaginal hysterectomy). The surgical procedure was initiated while the general trend for hysterectomy in the UK at that time was abdominal hysterectomy. We have tried to evaluate our experience in a district general hospital in the United Kingdom.

\section{Materials and methods}

The case records of 363 women undergoing various forms of laparoscopic hysterectomies were reviewed at 
the Princess Alexandra hospital, Harlow, England, from 1 January 1993 to 31 January 2002. Laparoscopic hysterectomies were divided into four surgical types (Table 1).

A three-port laparoscopic technique was carried out with a $12-\mathrm{mm}$ umbilical port (Storz), two $5-\mathrm{mm}$ ports on the operator side and a 5-mm port on the side opposite to the operating surgeon slightly lower than the umbilical port. If ENDO GIA (Autosuture) clips were used, then the two lateral $5-\mathrm{mm}$ ports were substituted with 10-mm ports. A Storz 10-mm laparoscope was used. Haemostasis was achieved with monopolar and bipolar diathermy, ENDO GIA clips or a combination of both. In cases where ENDO GIA clips were not used, bipolar diathermy and haemostatic scissors with monopolar diathermy were used. A single dose of Augmentin $1.2 \mathrm{~g}$ was given intravenously intra-operatively. Post-operatively, analgesia was administered in form of a morphine PCA infusion pump. The catheter inserted during surgery was retained till the next day. Patients were reviewed daily and, subject to satisfactory recovery, were discharged from the hospital the next day or the day after.

\section{Results}

Over a 9-year period, 363 hysterectomies were performed by a single first surgeon with the help of laparoscopic techniques. The indications for laparoscopic hysterectomy were for benign conditions only and included dysfunctional uterine bleeding, fibroid uterus, cases where vaginal hysterectomy was not possible, endometriosis, chronic pelvic pain, pelvic relaxation involving removing of adnexae and ovarian abnormalities. Laparoscopic hysterectomy was performed under general anaesthesia in a low-lithotomy position. The patient's ages ranged between 30 and 70 (mean 45) years. Indications for surgery included benign uterine conditions and malignancy that had not been detected prior to surgery. The average duration of stay varied between 2 and 3 days post-surgery, and patients were followed up 6 weeks later. They were also followed up over a longer period if any complications occurred. Uterine size varied between 5 and 16 weeks (mean 9.1) and the uterine descent which was assessed clinically in the pre-operative

Table 1 Classification of the procedure

\begin{tabular}{ll}
\hline Technique & Number (363) \\
\hline Type1: Laparoscopic subtotal hysterectomy & \\
Type 2: Laparoscopic-assisted vaginal & 1 \\
hysterectomy $^{\mathrm{b}}$ & 22 \\
Type 3: Laparoscopic hysterectomy $^{\mathrm{c}}$ & 297 \\
Type 4: Laparoscopic total hysterectomy &
\end{tabular}

${ }^{\mathrm{a}}$ Dissection to the level of the uterine body including uterine vessels

${ }^{\mathrm{b}}$ Dissection to the level of the uterine vessels

${ }^{\mathrm{c} D i s s e c t i o n}$ of the cardinal and uterosacral ligaments

${ }^{\mathrm{d}}$ Dissection of the uterosacral ligaments with laparoscopic opening of the vagina assessment clinic was generally limited. Operating time varied between 60 and 180 (mean 86.4) min (Table 2).

Five women stayed for longer than 7 days. Two of these cases were ureteric trauma; one woman had a haematoma and two women, being old, waited for a place in a residential home. Between 1 January 1993 and 31 December 1995, ENDO GIA was used more often while from 1996 onwards the use of the bipolardiathermy was predominant - the reason being budgetary. Table 3

In the subgroup of LAVH (laparoscopic assisted vaginal hysterectomy) cases, one case was abandoned due to uterine size and converted to an abdominal hysterectomy, another case was complicated with significant intra-operative bleeding (exceeding $500 \mathrm{ml}$ ) and in a third case, there was a post-operative haematoma formation. In the subgroup of laparoscopic hysterectomies, there was one case of superficial bowel injury, which was sutured by laparoscopic techniques as a precautionary measure. There was an additional case of ureteric damage due to undue thermal exposure to bipolar current while dissecting dense adhesions, which required reimplantation. There was a case of uretero-vaginal fistula, which was detected post-operatively and dealt with conservatively. Another case of vesico-vaginal fistula required repeat surgery and repair of the bladder with ureteric stents. In the same subgroup, there were eight cases of significant intra-operative bleeding $(>500 \mathrm{ml})$, six of which necessitated laparotomy. There were ten cases of delayed bleeding, which included five cases of vault haematoma managed conservatively and two cases of pelvic haematoma, one of which was drained by laparotomy. Finally, in the subgroup of total laparoscopic hysterectomies, there were two cases of intraoperative bleeding and three cases of delayed bleeding complications.

There was one death in group 3. The procedure was abandoned at an early stage due to very heavy bleeding, and a total abdominal hysterectomy was done. The

Table 2 Patients dermographics and details of procedure

\begin{tabular}{ll}
\hline Variable & Mean (range) \\
\hline Patient age & $45(30-70$ years $)$ \\
Operating time & $86.4(60-180$ min $)$ \\
Length of hospitalisation & $2.7(1-11$ days $)$ \\
Uterine size & $9.1(5-16$ weeks $)$ \\
\hline
\end{tabular}

Table 3 Techniques

\begin{tabular}{lll}
\hline $\begin{array}{l}\text { Type of } \\
\text { hysterectomy }\end{array}$ & Method of haemostasis & Number \\
\hline Type 1: total 1 & Diathermy only & \\
& ENDO GIA mainly \pm diathermy & 1 \\
Type 2: total 22 & Diathermy only & 14 \\
& ENDO GIA mainly \pm diathermy & 8 \\
Type 3: total 297 & Diathermy only & 212 \\
& ENDO GIA mainly \pm diathermy & 85 \\
Type 4: total 43 & Diathermy alone & 35 \\
& ENDO GIA & 8 \\
\hline
\end{tabular}


patient post-operatively continued to worsen, and this was followed by two laparotomies by surgeons, the first being negative while the second identified presence of a bowel leak. This patient died in the hospital. Table 4, 5

Three cases of endometrial carcinoma in stage 1 were detected on histological examination. These were initially diagnosed on endometrial biopsy as benign pathology.

\section{Discussion}

Laparoscopic hysterectomy seeks to bring the benefits of vaginal surgery to those who otherwise require a laparotomy by avoiding the need for an abdominal incision. The first laparoscopic hysterectomy was reported by Reich et al. [7] in 1989. Laparoscopic hysterectomy does require a longer learning curve [8], and once mastered, these techniques allow the surgeon to explore other areas of pelvic surgery. In a district general hospital environment, acceptance of a laparoscopic procedure takes longer and is often compared with open hysterectomies due to additional theatre time and cost factors.

There are many factors responsible for the uptake of laparoscopic hysterectomy, especially in district general hospitals. Initial costs of the instrumentation, limited medical personnel in training to achieve this long learning curve and initial longer operative periods thereby curtailing the number of cases done in an operative list. Studies have shown that time for surgery significantly reduced over 12-24 months of its practice [9]. Cost being one of the main factors as well as the time involved in surgery, many hospitals and surgeons opt for a laparotomy approach. The cost of the laparoscopic procedure is greater during the operation, with longer operating room time and cost of disposable instruments [3]. However, the total cost of treatment will turn out to be smaller, as indicated by various studies $[10,11]$. Our study did show that the mean duration of stay was 2.7 for laparoscopic hysterectomy days as compared to the average duration of stay for a total abdominal hysterectomy being around 5 days.

Also, postoperative benefits have been shown in many studies [12-14] regarding the value of minimally invasive surgery, with reduced hospital stay, early return to normal activities and early return to work in the community. We did not look into the indirect costs and savings, i.e. the amount of money saved due to faster return to work after laparoscopic hysterectomy. But if we assume that the patient returns to work earlier, the savings to society could make the overall cost of the laparoscopic procedure less.

Our overall complication rate was $8.5 \%$. This compares favourably with the complication rates with abdominal, vaginal and laparoscopic hysterectomies in various studies [15]. Mortality rates for hysterectomy for benign disorders are low but do occur [16]. Literature suggests that the commonest complication of hysterectomy is haemorrhage $(4.7 \%)$ regardless of the route of surgery $[15,17]$. Our rate of intra-operative haemorrhage compares favourably $(3.03 \%)$ with other studies. Our rate of late bleeding complications. including haematoma formation, was $3.8 \%$. Other authors indicate that it is very common to detect relatively small haematoma in cases of laparoscopic hysterectomies [18], demonstrating that a large number of patients will have a small collection of blood in the pelvis $(<20 \mathrm{ml})$ while $16 \%$ of patients will have febrile episodes associated with larger collections. Other peri-operative complications include bladder injuries $(0.6 \%$ compared with $0.8 \%$ in our study). We recommend that certain precautions be taken

Table 4 Synopsis on intra-operative complications

\begin{tabular}{|c|c|c|c|c|c|c|c|c|}
\hline \multirow[t]{2}{*}{ Type of surgery } & \multicolumn{7}{|c|}{ Complications } & \multirow[t]{2}{*}{ Number } \\
\hline & TAH & $\begin{array}{l}\text { Bowel } \\
\text { injury }\end{array}$ & Ileus & $\begin{array}{l}\text { Ureter } \\
\text { injury }\end{array}$ & $\begin{array}{l}\text { Bladder } \\
\text { Injury }\end{array}$ & $\begin{array}{l}\text { Intra-op. } \\
\text { (bleeding }>500 \mathrm{ml} \text { ) }\end{array}$ & $\begin{array}{l}\text { Late bleeding } \\
\text { complication }\end{array}$ & \\
\hline Type 1: 1 case & 0 & 0 & & 0 & 0 & 0 & 0 & 0 \\
\hline Type 2: 22 cases & 1 & 0 & & 0 & 0 & 1 & 1 & 2 \\
\hline Type 3: 297 cases & 8 & 2 & 1 & 2 & 3 & 8 & 10 & 26 \\
\hline Type 4: 43 cases & 0 & 0 & & 0 & 0 & 2 & 3 & 5 \\
\hline
\end{tabular}

TAH Total Abdominal hysterectomy

Table 5 Late complications: 6 weeks to 6 months

\begin{tabular}{lllll}
\hline & Late complications & $N<6$ weeks & $N>6$ weeks & Total \\
\hline 1 & Vault prolapse & 0 & 3 & 3 \\
2 & Symptomatic bowel dysfunction & 2 & 2 & 4 \\
3 & Recurring pain & 4 & 4 & 4 \\
4 & Hernia (port) & 2 & 0 & 2 \\
5 & Vesico-vaginal fistula & 1 & 0 & 1 \\
6 & Adhesions/repeat laparoscopic adhesiolysis & 0 & 2 & 2 \\
7 & Early endometrial carcinoma & 3 & 0 & 3 \\
8 & Menopausal symptoms & 12 & 0 & 12 \\
9 & Ureteric fistula & 1 & 0 & 1 \\
\hline
\end{tabular}


to avoid this. The bladder should remain empty during the procedure by the presence of an in-dwelling catheter. Careful separation of the bladder and application of forceful traction on the uterus to enable easier dissection of the bladder are recommended. It is also important to recognise damage to the bladder early, especially in cases of difficult bladder dissection where filling the bladder with methylene blue dye may help to spot the leak. We detected one bladder injury in the post-operative period.

In literature, the incidence of intestinal injuries in all types of laparoscopic hysterectomy is $0.1 \%,[15,17]$ while our incidence with total laparoscopic hysterectomy was $0.27 \%$. This compares with another studies with total laparoscopic hysterectomies ranging from $0 \%$ to $1 \%$ [19-23]. Both cases in our study occurred in cases of pelvic adhesions and with difficult dissection. This rate has been reported to be higher after abdominal hysterectomy $(2.4 \%)$ than after laparoscopic hysterectomy $(1.1 \%)$ or vaginal hysterectomy $(0.3 \%)$ [24]. Kovac et al. [24] reported a prospective study of 1,427 women and demonstrated that there is a higher risk of one or more complications after abdominal hysterectomy $(9.3 \%)$ than after laparoscopic-assisted vaginal hysterectomy $(3.6 \%)$ or vaginal hysterectomy $(5.3 \%)$.

Ureteric injuries are rare, averaging $0.04 \%$ in the literature [17]. Our incidence was $0.5 \%$ in cases of total laparoscopic hysterectomy and occurred prior to 2000 . All ureteric traumas were in cases having total laparoscopic hysterectomy and compares with another studies of similar surgery $0.2-1 \%$ [19-23]. Both the injuries were in cases of severe endometriosis with adhesions and occurred between 1993 and 1998. The complications occurred with total laparoscopic hysterectomies, in cases without prior selection and in the very early learning curve of the surgeon. There have been none in the past 7 years. This type of injury is extremely difficult to diagnose and often is a diagnosis made post-operatively. Preventive measures include a good detailed clinical history and examination, identifying the ureters and avoiding extensive dissection in its close proximity. We have avoided any ureteric damage in the past 5 years with the use of ureteric stents during the surgery, which we do if difficult dissection is anticipated.

Postoperative ileus is rare in laparoscopic hysterectomy. It is a known complication of laparotomies and its incidence increases with very difficult laparotomies. Dicker et al. [25] reported ileus in $0.2 \%$ of vaginal hysterectomies whereas laparoscopic-assisted vaginal hysterectomies lead to the lowest rate of ileus $(0.1 \%)$ [17]. Our incidence of ileus was $0.27 \%$.

Our rate of re-operation was $0.5 \%$, which is significantly lower than the $1.6 \%$ in the literature.

Our results of laparoscopic hysterectomy are comparable with those reported in the literature. We could not identify any difference in complication rate by the use of ENDO GIA staples instead of diathermy. Except for saving a few minutes, the cost factor increased due to the ENDO GIA being disposable. Though the perioperative costs of laparoscopic hysterectomy and the operative time is higher, in the long term, with fewer days of hospital stay in busy district general hospitals, the laparoscopic procedure may address the issue of making more room for patients. Also, with greater motility and less tissue handling, the morbidity is significantly reduced, and we assume that the incidence of thromboembolic episodes may be fewer. There is no doubt that society benefits from less recovery care needed and faster mobilisation and return to work in cases of laparoscopic hysterectomy.

\section{Conclusion}

The major drawback in district general hospitals is the long learning curve, which needs to be tolerated in the face of persistent, increasing operative workload. It is during this learning curve in wich complications occur that makes change extremely difficult. The rates of hysterectomy keep decreasing due to conservative management, and training in minimal access surgery is still limited .The great benefits of minimal access surgery should be offered as an alternative to abdominal hysterectomy. It is important to dramatically increase the uptake of laparoscopic hysterectomy from a meagre $4.8 \%$ [10] in the UK if we aim to achieve any form of significant change in practice and training for such an important technique.

\section{References}

1. Hospital Episode Statistics (1994-1995) Department of Health, London

2. Vessey MP, Villard-Mackintosh L, McPherson K, Coulter A, Yeates D (1992) The epidemiology of hysterectomy: findings in a large cohort study. $\mathrm{Br} \mathbf{J}$ Obstet Gynaecol 99:402-407

3. Redburn JC, Murphy MFG (2001) Hysterectomy prevalence and adjusted cervical and uterine cancer rates in England and Wales. Br J Obstet Gynaecol 108:388-395

4. Dicker RC, Greenspan JR, Strauss LT et al (1982) Complications of abdominal and vaginal hysterectomy among women of reproductive age in the United States. Am J Obstet Gynecol 144:841-847

5. Lowell L, Kessler A (2000) Laparoscopic assisted vaginal hysterectomy, a substitute for abdominal hysterectomy? J Reprod Med 45:738-742

6. Grant NF (1992) Infertility and endometriosis: comparison of pregnancy outcomes with laparotomy versus laparoscopic techniques. Am J Obstet Gynecol 166:1072-1081

7. Reich H, DeCaprio J, McGlynn F (1989) Laparoscopic hysterectomy. J Gynecol Surg 5:213

8. Rosen D, Cario G (1998) The learning curve for laparoscopic hysterectomy. Gynec Endosc 7:289-294

9. Cario G, Carlton M (2001) Total laparoscopic hysterectomy with laparosonic coagulating shears: a retrospective report of 200 consecutive cases: Aust N Z J Obstet. Gynaecol 41(3):307

10. Tsaltas J, Magnus A et al (1997) Med J Aust 166:205

11. Nezhat C, Bess O et al (1994) Hospital cost comparison between abdominal, vaginal and laparoscopy assisted vaginal hysterectomies. Obstet Gynaecol 83:713-716

12. Rosen D, Caio G (1997) Return to work following laparoscopic hysterectomy. Gynaecol Endosc 6:261-264

13. Reisner J, Miollis M (1997) Laparoscopically assisted vaginal hysterectomy in a community hospital. J Reprod Med 2:542-546

14. Ryan MM (1997) Hysterectomy: social and psychosexual aspects. BaillieresClin Obstet Gynaecol 11:23-26 
15. Cosson M, Lambaudie E et al (2001) Vaginal laparoscopic or abdominal hysterectomies for benig disorders: immediate and early post-oerative complications. Eur J Obstet Gynaecol Reprod Biol 98:231-236

16. Loft A, Andersen T et al (1991) Early post operative mortality following hysterectomy. A Danish population based study. 1977-1981. Br J Obstet Gynaecol 98:147-154

17. Rempen A (1996) Laparoscopic assistance at vaginal hysterectomy: a literature review. Arch Gynecol Obstet 258:55-64

18. Roesn D, Cario G (1997) Vault Haematoma following laparoscopic hysterectomy. Aust NZ J Obstet Gynaecol 37(2):220222

19. Garry R, Fountain J, Mason S et al (2004) The eVALuate study: two parallel randomised trials, one comparing laparoscopic with abdominal hysterectomy, the other comparing laparoscopic with vaginal hysterectomy. Br Med J 328:129

20. Cook JR, O'Shea RT, Seman EI (2004) Laprovaginal hysterectomy: a decade of evolution. Aust NZ J Obstet Gynaecol 44(2):111-116
21. Wattiez A, Soriano D, Cohen SB et al (2002) The learning curve of total laparoscopic hysterectomy: comparative analysis of 1647 cases. J Am Assoc Gynecol Laparosc 9(3):339345

22. Shen CC, Wu MP, Kung FT et al (2003) Major complications associated with laparoscopic - assisted vaginal hysterectomy: a ten year experience. J Am Assoc Gynecol Laparosc 10(2):147153

23. Makinen J, Johansson J, Tomas C et al (2001) Morbidity of 10110 hysterectomies by type of approach. Hum Reprod $16(7): 1473-1478$

24. Kovac RS (2000) Hysterectomy outcomes in patients with similar indications. Obstet Gynecol 95(6):787-793

25. Dicker R, Greenspan J et al (1982) Complications of abdominal and vaginal hysterectomy among women of reproductive age in United States. Am J Obstet Gynecol 144:841-848 